\title{
PREDICTION OF SPATIALLY DISTRIBUTED SEISMIC DEMANDS IN SPECIFIC STRUCTURES: STRUCTURAL RESPONSE TO LOSS ESTIMATION
}

\author{
Brendon A Bradley ${ }^{*}$, Rajesh P Dhakal, Gregory A MacRae, Misko Cubrinovski \\ Department of Civil and Natural Resources Engineering, University of Canterbury, Private Bag 4800, \\ Christchurch 8020, New Zealand \\ *Corresponding author: $\mathrm{Ph}+64-3-3667001$ ext 7673; Fax: +64-3-364 2758; \\ Email: bab54@student.canterbury.ac.nz
}

\begin{abstract}
A companion paper has investigated the effects of intensity measure (IM) selection in the prediction of spatially distributed response in a multi-degree-of-freedom structure. This paper extends from structural response prediction to performance assessment metrics such as: probability of structural collapse; probability of exceeding a specified level of demand or direct repair cost; and the distribution of direct repair loss for a given level of ground motion. In addition, a method is proposed to account for the effect of varying seismological properties of ground motions on seismic demand that does not require different ground motion records to be used for each intensity level. Results illustrate that the conventional IM, spectral displacement at the first mode, $S_{d e}\left(T_{1}\right)$, produces higher risk estimates than alternative velocity-based IM's, namely spectrum intensity, $S I$, and peak ground velocity, $P G V$, because of its high uncertainty in ground motion prediction and poor efficiency in predicting peak acceleration demands.
\end{abstract}

\section{KEYWORDS}

Deaggregation, seismic demand correction, loss estimation, demand hazard, collapse hazard.

\section{INTRODUCTION}

Contemporary building-specific seismic performance and loss estimation methodologies [e.g. 1, 2, 3] following the Pacific Earthquake Engineering Research (PEER) Centre performance-based earthquake engineering (PBEE) framework [4] use ground motion intensity measures (IM's) as the link between seismic hazard and structural response. The use of IM as an interim variable is beneficial in that it also provides a separation between the equally complex tasks of seismic hazard and seismic response analyses, which are generally performed by different expert personnel. An alternative to the IM based approach is the direct estimation of seismic demands as a function of earthquake source and local site properties (e.g. [5]). This approach is appealing in that no information is 'lost' by representing a (complex) ground motion time history by some (simplified) IM. However, because the process of seismic hazard and seismic response analyses are coupled in this approach, the analyst must have expertise in, and access to: earthquake fault and background seismicity data of the region of interest; strong-ground motion prediction and mixed effects regression procedures; and seismic response analyses. This approach generally uses recorded ground motion records as input for the seismic responses, although simulated ground motions can also be used in a similar fashion (e.g. [6, Chapter 6]). The broad expertise and information required in this approach, as well as its significantly increased computational demands, 
renders it impractical at present for all but the most important of structures. This manuscript is solely focused on the IM-based approach. It is important to note however that the information 'lost' due to the use of an inappropriate IM will generally lead to higher uncertainty in seismic response analysis, and therefore an increase in the mean annual frequency of exceeding some level of demand [6, Chapter 6] (assuming the median response is not significantly underestimated).

The aforementioned loss estimation methodologies adopting the IM-based approach also account for the spatially distributed location of components in the structure by using a vector of seismic demands (so-called engineering demand parameters, EDP's) to describe the response. It is therefore desirable to have an IM that can provide a precise (efficient) and unbiased (sufficient) prediction of the spatially distributed demands in structures. In addition, it is also important that the IM can itself be predicted with a relatively small uncertainty (predictability). Bradley et al. [7] investigated the efficiency, sufficiency, and predictability of common IM's when conducting seismic response analysis of a 10 storey RC frame structure. Bradley et al. illustrated that common ground motion IMs are not sufficient with respect to all of earthquake magnitude, $M_{w}$, source-to-site distance, $R$, and epsilon, $\varepsilon$, when predicting peak interstorey drift ratios and peak floor accelerations at spatially distributed locations in a structure, and thus bias will be introduced if the $M_{w}, R, \varepsilon$ distribution of the ground motion suite used is different than that of seismic hazard deaggregation.

This paper is intended to follow-on from Bradley et al. [7] with particular focus on: (1) 'correction' of the seismic demand distributions to account for insufficiency of the adopted IM; (2) determination of the annual probability of exceeding a specified level of demand (demand hazard); (3) determination of the distribution of direct economic loss for a given level of IM; (4) deaggregation of the expected direct economic loss for a given level of IM; and (5) determination of the annual probability of exceeding a specified level of direct economic loss (loss hazard). Explicit discussion is also given to the efficiency, sufficiency, and predictability of intensity measures in cases where results presented oppose current ideas as published in literature.

The structure used in the analyses presented herein is a 10 storey RC frame structure which is further described in Bradley et al. [7].

\section{HAZARD DEAGGREGATION AND GROUND MOTION SELECTION FOR A RANGE OF IM LEVELS}

Ground motion intensity measures (IM's) provide the link between the exceedance rate of various levels of ground motion (from a seismic hazard curve) and structural response (from seismic response analysis). Consideration of an appropriate IM is discussed and investigated for the seismic response of a 10 storey $\mathrm{RC}$ frame in a companion paper [7]. The five different IM's used here are: peak ground acceleration $(P G A)$; peak ground velocity $(P G V)$, elastic spectral displacement $\left(S_{d e}\right)$; inelastic spectral displacement $\left(S_{d i}\right)$; and spectrum intensity $(S I)$. This selection was based on: (1) IMs which have been used by other researchers; and (2) IMs that have 'robust' ground motion prediction equations which can be used to determine ground motion hazard curves for the adopted IM. Bradley et al. [7, Figure 1] illustrate the hypothetical site and the seismic hazard curves obtained for the five different IMs.

Selection of ground motions for seismic response analysis should be based on those which are most likely to occur at the site in the future (which obviously is unknown). Deaggregation of the seismic hazard for a given level of ground motion, IM $=i m$, can be used to determine the magnitude $\left(M_{w}\right)$, distance $(R)$, and epsilon $(\varepsilon)$ statistics of the ground motion hazard, which can then be used as a 'target' for selecting ground motion records. Because 
different rupture scenarios $\left(M_{w}, R, \varepsilon\right)$ have different probabilities of occurrence then deaggregation of the seismic hazard is dependent on the specific value of the IM considered.

The fact that the results of seismic hazard deaggregation are a function of the IM level (as well as the IM adopted) indicates that if a wide range of IM levels is considered (corresponding to a range of exceedance probabilities of interest), then the deaggregation statistics may change significantly. Thus, different ground motion record suites should be used for different IM levels. Such an approach was adopted by, for example, Goulet et al. [2] who used seven different ground motions suites for seven IM levels from 0.1-0.82g $S_{a}(T=1.0 \mathrm{~s})$. The need to use different ground motion suites at different IM levels to reduce bias is conditional on the insufficiency of the adopted IM to a specific parameter (i.e. $M_{w}, R$, $\varepsilon)$ from the hazard deaggregation. If an IM is sufficient for all $M_{w}, R, \varepsilon$ then the seismic response of some structure to ground motions scaled to IM is conditionally independent of $M_{w}, R, \varepsilon$. However, Bradley et al. [7] illustrate that common IMs used in seismic response analysis do not exhibit sufficiency with respect to all of $M_{w}, R, \varepsilon$ for predicting peak interstorey drift ratios and peak floor accelerations.

Figures 1a-1c illustrate the mean and mean \pm one standard deviation values of $M_{w}, R$, and $\varepsilon$ obtained from hazard deaggregation for the site as a function of PGA annual exceedance probability. It is seen that as the probability of exceedance reduces, resulting in larger ground motions, both the mean magnitude and epsilon values increase, while the distance decreases. Also shown in Figures 1a-1c are the mean and mean \pm one standard deviation values of $M_{w}, R$, and $\varepsilon$ of the ground motion suite used by Bradley et al. [7], which was also adopted in this study for all intensity levels. It is clear that the properties of the ground motion suite can be quite different than the hazard deaggregation as the exceedance probability varies. Figures $1 \mathrm{~d}-1 \mathrm{f}$ illustrate the variation in the mean values of $M_{w}, R$, and $\varepsilon$ for the five different IMs as a function of the probability of exceedance of the IM. While the same trends as mentioned above for PGA apply to all of the IMs, there is clearly variation in the mean values for a given probability of exceedance. This can be explained with reference to the usual scenario in which small magnitude events at close distances dominate a uniform hazard spectra (UHS) at short vibration periods (e.g. $P G A$ ), while larger magnitude events at farther distances tend to dominate the UHS at longer vibration periods (e.g. $S_{d e}$ and $S_{d i}$ ). In this study, the seismic response of the case study structure is investigated over a range of IM levels. Rather than using different ground motion suites for different IMs and IM levels, a single ground motion suite is used, and the distribution of the seismic demand obtained is 'corrected' to account for the difference between the deaggregation and ground motion suite $M_{w}, R$, and $\varepsilon$ statistics.

Bradley et al. [7] illustrate that even for a given IM level it maybe difficult to obtain a ground motion suite where the $M_{w}, R$, and $\varepsilon$ statistics closely match some 'target' statistics from deaggregation. In such cases, 'correction' of the seismic demand distribution due to IM insufficiency may also be necessary (particularly for loss estimation, where typically both interstorey drifts and floor accelerations are estimated). As will be shown in the following section, the effect of the 'correction' depends on the insufficiency of an IM with respect to (one or more of) $M_{w}, R$, and $\varepsilon$, and the difference between the deaggregation and ground motion suite statistics. Hence, with reference to Figures 1a-1c, in this study, the corrections will be most significant at low probabilities of exceedance where the largest difference between hazard deaggregation and ground motion properties is observed. 

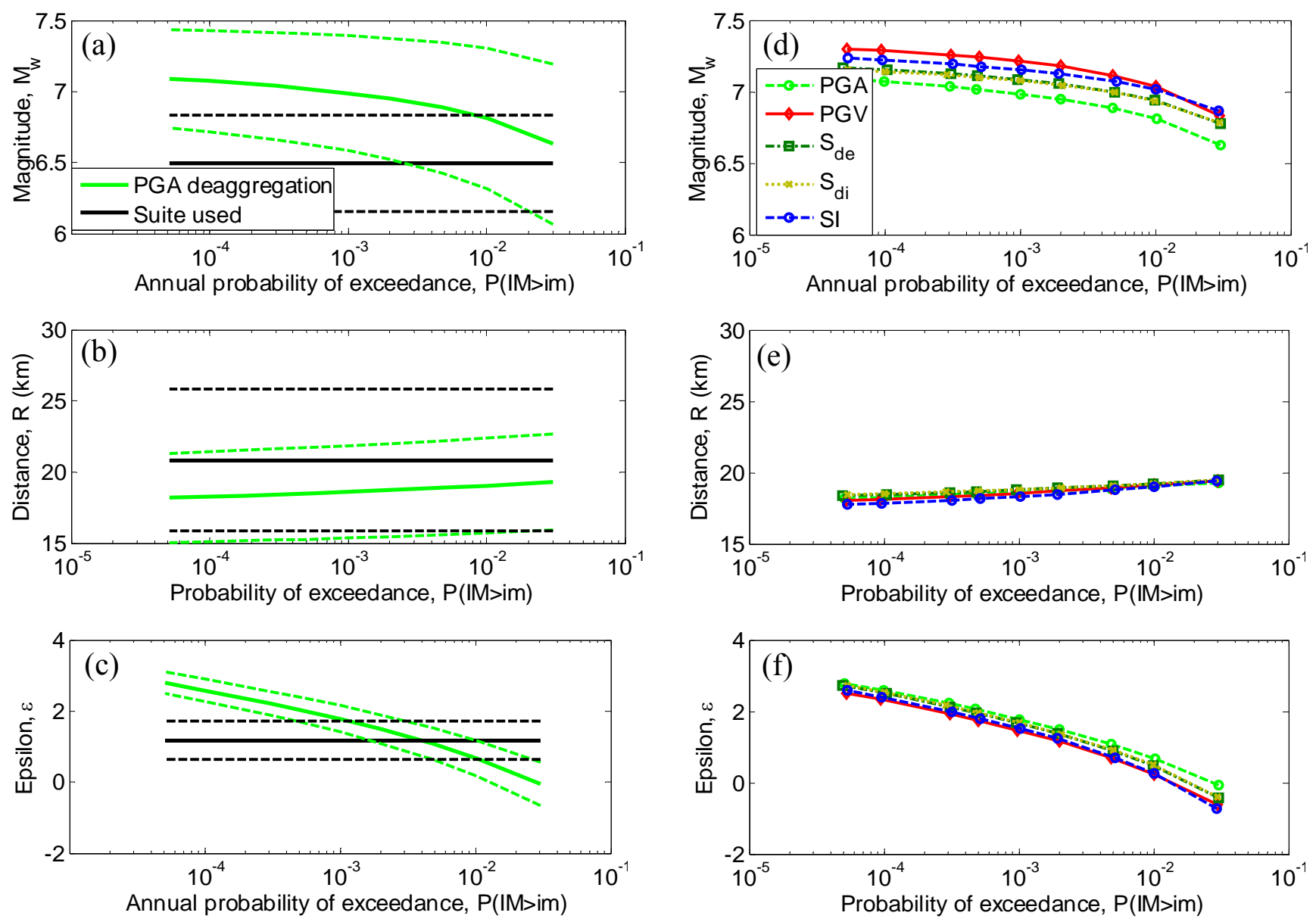

Figure 1: Comparison of the mean (solid line) and \pm one standard deviation (dashed line) of (a) magnitude; (b) source-to-site distance; and (c) epsilon values from hazard deaggregation of PGA with the ground motion suite used. Variation of the mean (d) magnitude; (e) distance; and (f) epsilon with annual exceedance probability for the different IMs.

\section{CORRECTING SEISMIC DEMAND DISTRIBUTIONS}

Bradley et al. [7] illustrated that none of the IMs examined in this manuscript are sufficient with respect to all of $M_{w}, R, \varepsilon$ for all peak interstorey drifts and peak floor accelerations monitored in the case-study structure. The advantage of having a sufficient IM with respect to some parameter $x$, is that the distribution of demands obtained from the finite number of seismic response analyses, would not be (practically speaking) dependent on the distribution of $x$ from the suite of ground motions used (i.e. $f(E D P \mid I M) \cong f(E D P \mid I M, x)$ ). However, as no IMs were entirely sufficient with respect to $M_{w}, R, \varepsilon$ then in certain instances the properties of the ground motion suite used will affect the results and therefore careful ground motion selection is pertinent. As noted by Bradley et al. [7], despite the large database of ground motion records available for time-history analysis it may not be possible to obtain a specified number of ground motions which accurately match the distribution of $M_{w}, R, \varepsilon$ obtained from hazard deaggregation for the specified level of IM (particularly as $M_{w}$ and $\varepsilon$ increase and $R$ reduces). In such cases it is possible to use the correlation between the observed EDPs and some parameter $x$ to 'correct' the distribution of $f(E D P \mid I M)$. The theory behind such a procedure is outlined in the following paragraphs. 


\section{Theory of the demand correction procedure}

From the result of multiple regression it is possible to obtain the mean of $\operatorname{lnEDP}$ as a function of $M_{w}, R, \varepsilon$ (i.e. $\mu_{\ln E D P \mid I M, M_{W}, R, \varepsilon}$ ) and then integrate over the distribution of $M_{w}, R, \varepsilon$ (i.e. $\left.f\left(M_{W}, R, \varepsilon\right)\right)$ from hazard deaggregation to obtain an unbiased estimate of the 'true' mean of the $\ln E D P \mid I M$ distribution as given in Equation (1):

$$
\hat{\mu}_{\ln E D P \mid I M}=\iiint_{M_{W}, R, \varepsilon} \mu_{\ln E D P \mid I M, M_{W}, R, \varepsilon} f\left(M_{W}, R, \varepsilon\right) d M_{W} d R d \varepsilon
$$

If it is however known that for the given EDP, IM is sufficient with respect to (for example) $M_{w}$ and $R$, then $\mu_{\ln E D P \mid I M, M_{W}, R, \varepsilon} \cong \mu_{\ln E D P \mid I M, \varepsilon}$, and Equation (1) simplifies to:

$$
\hat{\mu}_{\ln E D P \mid I M} \cong \int_{\varepsilon} \mu_{\ln E D P \mid I M, \varepsilon} f(\varepsilon) d \varepsilon
$$

Similarly, the standard deviation of the $\ln E D P \mid I M$ distribution can be obtained (also assuming sufficiency with respect to $M_{w}$ and $R$ ):

$$
\hat{\sigma}_{\ln E D P \mid I M}^{2} \cong \int_{\varepsilon}\left(\mu_{\ln E D P \mid I M, \varepsilon}^{2}\right) f(\varepsilon) d \varepsilon-\left(\hat{\mu}_{\ln E D P \mid I M}\right)^{2}
$$

Furthermore if as a first-order approximation, $\mu_{\ln E D P \mid I M, \varepsilon}$ is assumed to be a linear function of $\varepsilon$ and $f(\varepsilon)$ to have a normal distribution then Equations (2) and (3) become:

$$
\begin{gathered}
\hat{\mu}_{\ln E D P \mid I M} \approx \mu_{\ln E D P \mid I M, \varepsilon}\left(\mu_{\varepsilon}\right) \\
\hat{\sigma}_{\ln E D P \mid I M}^{2} \approx \sigma_{\ln E D P \mid I M, \varepsilon}^{2}+\left(b_{\varepsilon} \sigma_{\varepsilon}\right)^{2}
\end{gathered}
$$

where $\mu_{\varepsilon}$ and $\sigma_{\varepsilon}$ are the mean and standard deviation of $\varepsilon$ obtained from hazard deaggregation, and $b_{\varepsilon}$ is the coefficient in the linear regression $E[\ln E D P \mid I M]=a+b_{\varepsilon} \varepsilon$. Equations (1)-(5) form the theoretical basis for the 'correction' method proposed by Haselton [8] for correcting the collapse capacity of structures due to insufficiency with respect to $\varepsilon$. As noted by Haselton [8], Equations (4) and (5) can: (i) correct bias introduced if the distribution of the ground motion suite is significantly different from that of the hazard deaggregation; and (ii) potentially reduce dispersion (i.e. improve efficiency).

The following paragraphs generalise the result obtained above to the case of multiple insufficiency. When an IM is found to be insufficient with respect to multiple parameters then the multiple linear regression is of the form:

$$
E[\ln E D P \mid I M, \mathbf{X}]=a+\mathbf{b}_{\mathbf{x}} \bullet \mathbf{X}
$$

where $\mathbf{X}=\left(M_{W}, R, \varepsilon\right)$ is a vector of the parameters for which the IM is insufficient; $\mathbf{b}_{\mathbf{x}}=\left(b_{M_{W}}, b_{R}, b_{\varepsilon}\right)$; and “ $\bullet$ " is the vector 'dot' product. It is trivial to generalise Equations (4) and (5) in this case to:

$$
\begin{gathered}
\hat{\mu}_{\ln E D P \mid I M} \approx \mu_{\ln E D P \mid I M, \mathbf{X}}\left(\boldsymbol{\mu}_{\boldsymbol{X}}\right) \\
\hat{\sigma}_{\ln E D P \mid I M}^{2} \approx \sigma_{\ln E D P \mid I M, \mathbf{X}}^{2}+\boldsymbol{b}_{\boldsymbol{X}}{ }^{T} \Sigma_{\boldsymbol{X}} \boldsymbol{b}_{\boldsymbol{X}} \\
\hat{\sigma}_{\ln E D P_{i}, \ln E D P_{j} \mid I M} \approx \sigma_{\ln E D P_{i}, \ln E D P_{j} \mid I M, \mathbf{X}}+\boldsymbol{b}_{\boldsymbol{X}_{i}}^{\boldsymbol{T}} \Sigma_{\boldsymbol{X}} \boldsymbol{b}_{\boldsymbol{X}_{\boldsymbol{j}}}
\end{gathered}
$$


where $\Sigma_{X}$ is the covariance matrix of the parameters in $\boldsymbol{X}$ obtained from hazard deaggregation; and " $\boldsymbol{T}$ " is the vector transpose. Thus, in the case of multiple insufficiency regression is performed over a vector of components, and knowledge of the mean and covariance matrix of the hazard deaggregation is necessary. Figure 2 illustrates the (marginal) hazard deaggregation of $P G A$ at the 1/475 exceedance probability with respect to $M_{w}$ and $R$ (Figure 2a), and $M_{w}$ and $\varepsilon$ (Figure 2b). It can be seen from Figure 2a that there exists little correlation between $M_{w}$ and $R$, with a correlation coefficient of $\rho_{M, R}=0.09$. Figure $2 \mathrm{~b}$ illustrates that $M_{w}$ and $\varepsilon$ however exhibit a strong negative correlation, with $\rho_{M, \varepsilon}=-0.89$. The reason for this significant negative correlation between $M_{w}$ and $\varepsilon$ is that they have the same effect on observed ground motions at a particular site (and thus must be negatively correlated to produce a ground motion with $I M=i m)$. Large $M_{w}$ ruptures cause large ground motions which occur infrequently (compared to smaller $M_{w}$ ruptures), while small $\varepsilon$ values (i.e. around $\varepsilon=0$ ) cause smaller ground motions which occur more frequently (compared to, for example $\varepsilon=2$ ). Figure $2 \mathrm{c}$ illustrates the correlations between $M_{w}, R, \varepsilon$ as a function of the exceedance probability of $P G A$ for the site considered. While the correlations do vary with exceedance probability the general trends discussed above remain unchanged (similar trends were observed for the other IMs considered in this study). As the correlations are significant, then they should not be neglected when computing Equations (8) and (9) (which would lead to a significant underestimation of the 'corrected' dispersion of the $\ln E D P \mid I M$ distribution for the vector of EDP's).

Collapse probability may also be an important decision variable for performance and loss estimation [9], and it is therefore also necessary to correct the probability of collapse for IM insufficiency. As previously mentioned, Haselton [8] illustrated that collapse capacity estimated using $S_{d e}$ is insufficient with respect to $\varepsilon$ (and assumed sufficiency with respect to $\left.M_{w}, R\right)$. Haselton used an iterative procedure to determine the largest intensity of a specific ground motion at which the structure did not collapse, yielding 'collapse capacity' data which is continuous and can be 'corrected' using the aforementioned method. In the case of loss estimation, it is more desirable to use the seismic response analyses conducted with ground motions of $\mathrm{IM}=i m$ (which are used to get the distribution of loss, $f(L \mid I M)$ ), to directly estimate the collapse probability. This however leads to binary data of collapse or no-collapse for each ground motion record which requires minor modifications to the above correction procedure. Logistic regression [10] is used here to regress on the binary collapse data. The cumulative distribution of the logistic random variable (the collapse probability) is given by:

$$
P_{C \mid I M, X}(\boldsymbol{X})=\frac{\exp \left(a+\boldsymbol{b}_{\boldsymbol{X}} \bullet \boldsymbol{X}\right)}{1+\exp \left(a+\boldsymbol{b}_{\boldsymbol{X}} \bullet \boldsymbol{X}\right)}
$$

where $\boldsymbol{X}$ and $\boldsymbol{b}_{\boldsymbol{X}}$ have their same meanings as defined in Equation (6). The regression coefficients (i.e. $\boldsymbol{b}_{X}$ ) are obtained by (numerically) maximising the likelihood function for the logistic density [10]. Once the regression coefficients have been determined then the 'corrected' probability of collapse, $\hat{P}_{C \mid I M}$ can be obtained from $\hat{P}_{C \mid I M}=P_{C \mid I M, X}\left(\boldsymbol{\mu}_{\boldsymbol{X}}\right)$. 

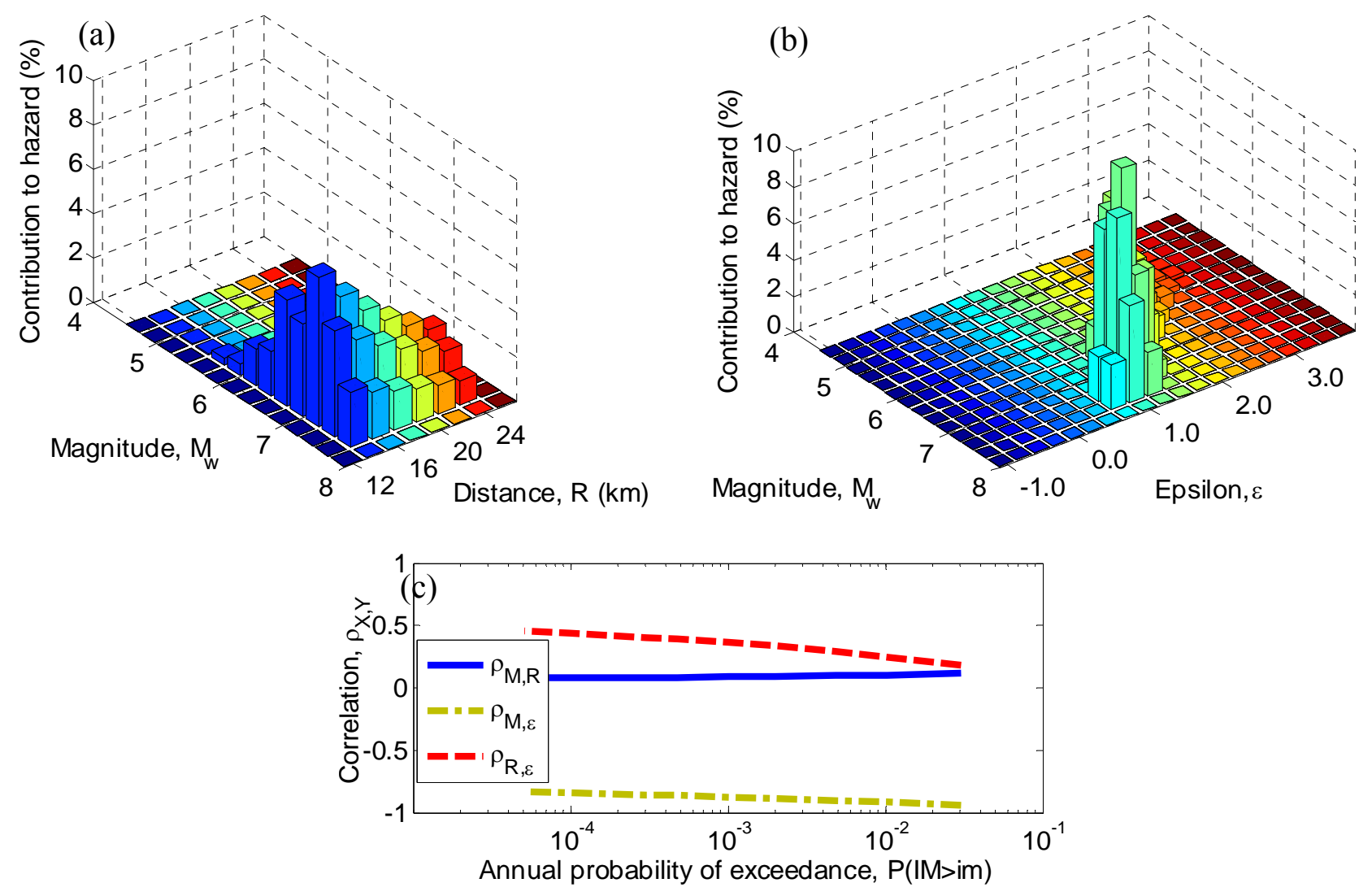

Figure 2: Illustration of the correlation within hazard deaggregation at the 1/475 exceedance probability for PGA: (a) magnitude and distance $\left(\rho_{M, R \mid I M}=0.09\right)$; and (b) magnitude and epsilon $\left(\rho_{M, \varepsilon \mid I M}=-0.89\right)$; (c) variation in the deaggregation correlations as a function of PGA annual exceedance probability.

As with the multiple linear regressions for correcting the demand distributions, significance tests should be performed on $\boldsymbol{b}_{\boldsymbol{X}}$ to confirm that there are statistically significant trends in the data. This particularly applies in the case where only a very small proportion of the ground motions cause structural collapse, which can produce statistically unstable regressions. If one or more variables in $\boldsymbol{X}$ are found to be statistically insignificant then the regression should be re-performed following removal of these variables.

While Equations (7)-(10) offer a method to correct the distribution of structural response, and collapse probability for an insufficient IM, that the procedure to do so becomes complex in the case of insufficiency with respect to more than one parameter. In particular, knowledge of the correlation matrix between $M_{w}, R, \varepsilon$ from the hazard deaggregation may not be available. In addition, for insufficiency with respect to multiple parameters the so-called curse of dimensionality [11] will mean that large suites of ground motions need to be used in order to obtain statistically stable 'corrected' results, as noted in a similar context by Baker [12]. Therefore, if a small suite of ground motion records is to be used (such as that proposed in current code guidelines), ground motions should be selected to match the deaggregation of the seismic hazard. If 'exact' ground motion selection to match seismic hazard deaggregation is not possible, the above procedure can be used. Furthermore, adequate ground motion selection will likely mean that the effect of the 'corrections' is not overly excessive and may be neglected if such a level of accuracy is not required.

For the hypothetical scenario considered in this study (i.e. a single line source) the deaggregation at a given IM level is relatively simple. In reality however, it is common for 
the total seismic hazard at a site to have significant contributions from multiple sources which may mean that the deaggregated $M_{w}, R, \varepsilon$ distribution is far from a multi-variate normal distribution, which has been assumed in the above correction procedure. In such cases, Equations (1) and (3), can be solved by summation over the deaggregation probability mass function (PMF) which is the typical output of seismic hazard deaggregation (e.g. Figures $2 \mathrm{a}$ and $2 b)$.

\section{Corrections for demand distribution and collapse probability}

Figures $3 \mathrm{a}$ and $3 \mathrm{~b}$ illustrate the regression of the maximum ground floor acceleration with $M_{w}$ and $R$ (a 3-dimensional regression with $\varepsilon$ was performed, but can obviously not be plotted). Simply from inspection it can be seen that $S_{d e}$ is notably less sufficient to $M_{w}$ and $R$ compared to $P G A$. Table 1 illustrates the numerical values of the regression shown in Figures $3 \mathrm{a}$ and $3 \mathrm{~b}$. It can be seen that when $P G A$ is used to predict the maximum ground floor acceleration $\left(a_{\max , 1}\right)$ the dependence on $M_{w}, R$ and $\varepsilon$ is statistically insignificant based on the F-test [10]. On the other hand, when $S_{d e}$ is used to predict $a_{\max , 1}, R$ and $\varepsilon$ are significant and the corrected and uncorrected values are $\exp (-0.569)=0.57 \mathrm{~g}$ and $\exp (-0.527)=0.59 \mathrm{~g}$, respectively. While the corrected demand in this case is only $4 \%$ different than that of the uncorrected demand (at an IM level with a 1/475 annual exceedance probability), one can appreciate that since the correction is a linear function of the differences in the magnitude, distance, and epsilon of the ground motions used in seismic response analysis and those from deaggregation, that larger corrections will occur where these differences are larger (i.e. at smaller exceedance probabilities as evident in Figure 1). It is also noted that when viewing Table 1 , the statistical significance of the ' $b$ ' values is dependent on both their magnitude as well as their uncertainty (due to the scatter in the data).

Figures $3 \mathrm{c}$ and $3 \mathrm{~d}$ illustrate the logistic regression of the collapse probability $\left(P_{C \mid I M}\right)$ on $M_{w}$ and $R$, with numerical values given in Table 1 . Figure $3 \mathrm{~d}$ illustrates that there is some dependence of collapse capacity on $M_{w}$ and $\varepsilon$ when scaling ground motions based on $S_{d e}$. Figure $3 \mathrm{c}$ also illustrates that there is a dependence on $M_{w}, R$ when using PGA-scaling. However, Table 1 illustrates that the $\mathrm{R}$ dependence is statistically insignificant (this is more easily examined by looking at the one-dimensional regressions against each of $M_{w}, R$ and $\varepsilon$ ).

The dependencies observed in Figure 3 are somewhat intuitive, with higher magnitude ground motions having richer low frequency content and weaker (relatively speaking) high frequency content compared with smaller magnitude ground motions. The trends regarding $\varepsilon$ are explained in detail by Baker and Cornell [13].

Results discussed in the following sections are all based on the use of the correction procedure (including statistical testing of significance) and hence for brevity the term 'corrected' is omitted. 

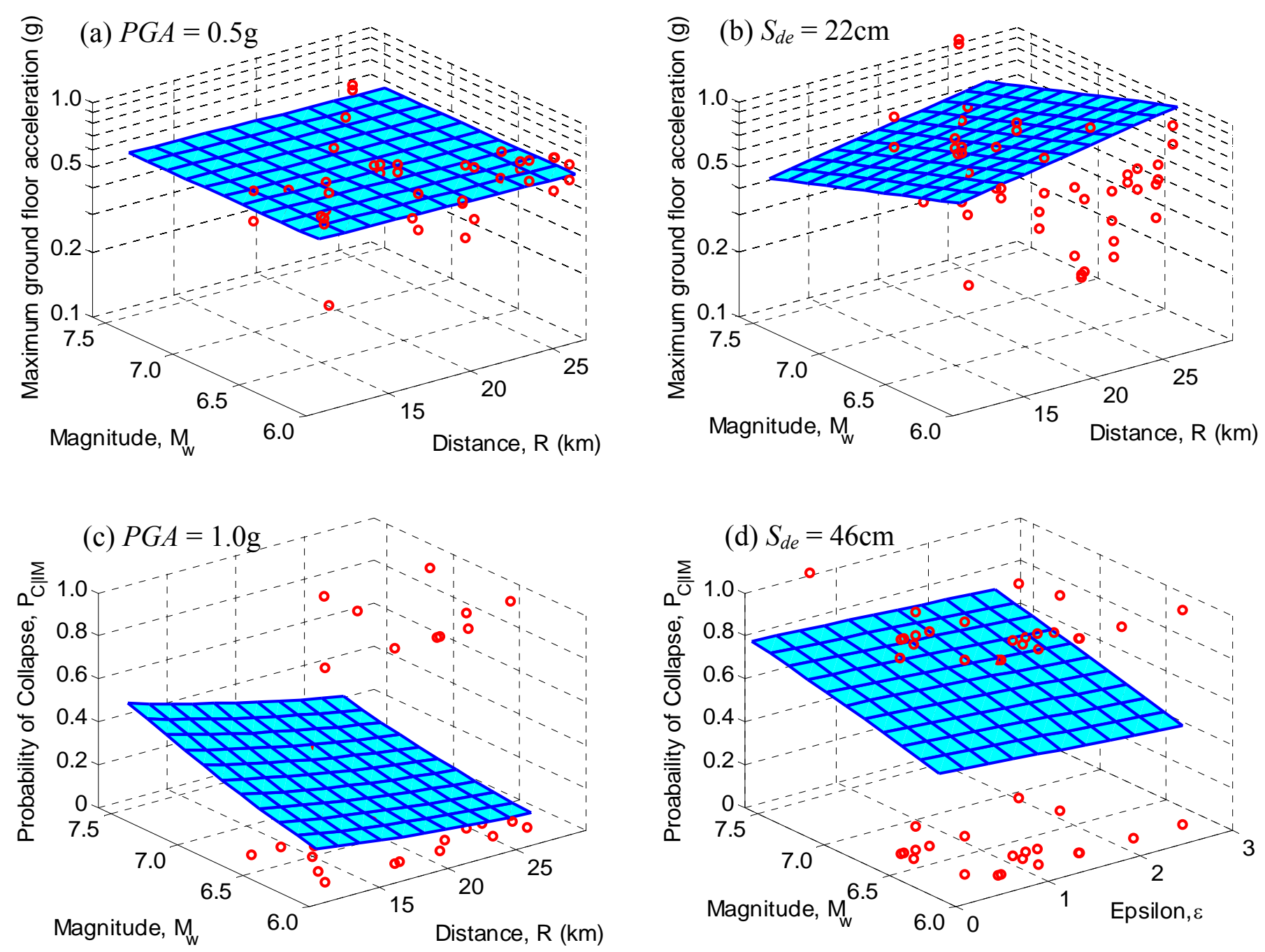

Figure 3: Illustration of: multivariate regression used to 'correct' the distribution of the demand given intensity for the maximum ground floor acceleration at the $1 / 475$ probability of exceedance using (a) PGA; and (b) Sde. Use of multivariate logistic regression to 'correct' the probability of structural collapse at the $10^{-4}$ exceedance probability using: (c) PGA; and (d) Sde.

Table 1: Illustration of correction procedure applied to the cases of Figure 3.

\begin{tabular}{|c|c|c|c|c|c|c|}
\hline EDP & IM & $\mathrm{a}$ & $\mathbf{b}_{\mathbf{x}}=\left(\mathrm{b}_{\mathrm{M}}, \mathrm{b}_{\mathrm{R}}, \mathrm{b}_{\varepsilon}\right)$ & $\begin{array}{c}\boldsymbol{\mu}_{\mathbf{x}}=\left(\mu_{\mathrm{M}}, \mu_{\mathrm{R}}, \mu_{\varepsilon}\right) \\
(\text { Figure 1) }\end{array}$ & $\begin{array}{c}\hat{\mu}_{\ln E D P \mid I M}(\mathrm{Eq}(7)) \\
\text { or } \hat{P}_{C \mid I M}(\mathrm{Eq}(10)) \\
\text { corrected }\end{array}$ & $\begin{array}{c}\mu_{\ln E D P \mid I M} \text { or } P_{C \mid I M} \\
\text { uncorrected }\end{array}$ \\
\hline$a_{\max , I}$ & $P G A$ & -0.56 & $(-0.02,-0.001,0.01)^{2}$ & $(6.95,18.7,1.49)$ & $-0.686(-0.685)^{3}$ & -0.686 \\
\hline$a_{\max , I}$ & $S_{d e}$ & 0.54 & $\left(-0.015^{1},-0.03,-0.53\right)$ & $(7.06,18.9,1.38)$ & -0.569 & -0.527 \\
\hline$P_{C \mid M}$ & $P G A$ & 0.32 & $\left(0.20,-0.08^{1},-1.18\right)$ & $(7.07,18.3,2.59)$ & 0.26 & 0.21 \\
\hline$P_{C \mid I M}$ & $S_{d e}$ & -3.77 & $(0.69,-0.015,-0.24)$ & $(7.15,18.5,2.49)$ & 0.56 & 0.64 \\
\hline
\end{tabular}

coefficient is statistically insignificant based on t-test at $\alpha=5 \%$ significance level

${ }^{2}$ all $\boldsymbol{b}_{\boldsymbol{X}}$ coefficients are statistically insignificant based on F-test at $\alpha=5 \%$ significance level

${ }^{3}$ values in brackets are those estimated using the (insignificant) regression equation 


\section{COLLAPSE AND DEMAND HAZARDS}

Using the suite of ground motions adopted for this study, seismic response analyses were conducted by scaling the ground motion records to nine IM values that had annual exceedance probabilities ranging from 0.03 to $5 \times 10^{-5}$. Figure 4 illustrates the mean scale factor of the ground motion suite (i.e. the average of the scale factors to scale each record to $I M=i m$ ) which was required to scale the ground motions to IM values corresponding to the nine different exceedance probabilities. As one would expect, reducing the exceedance probability causes an increase in ground motion intensity and therefore an increase in the mean scale factor. It is also evident that for a given exceedance probability the mean scale factor of the ground motion suite is not the same when different IMs are used. Furthermore, the difference between the scale factors using different IMs (for a given exceedance probability) increases as the exceedance probability reduces. For example, at $\mathrm{P}_{\mathrm{IM}>i m}=0.03$ the ratio between the mean scale factors using $S_{d e}$ and $S I$ is $0.77 / 0.66=1.17$, while at $\mathrm{P}_{\mathrm{IM}>i m}=5 \times 10^{-5}$ the ratio is $6.2 / 4.1=1.51$. It should be clear from results presented in Bradley et al. [14, Table 3] that the difference between the mean scale factor for the different IMs is strongly related to the predictability of the IM (i.e. the uncertainty in the ground motion prediction equation, GMPE), since a large uncertainty in the GMPE will significantly increase the hazard at low $\mathrm{P}_{\mathrm{IM}>i m}$.

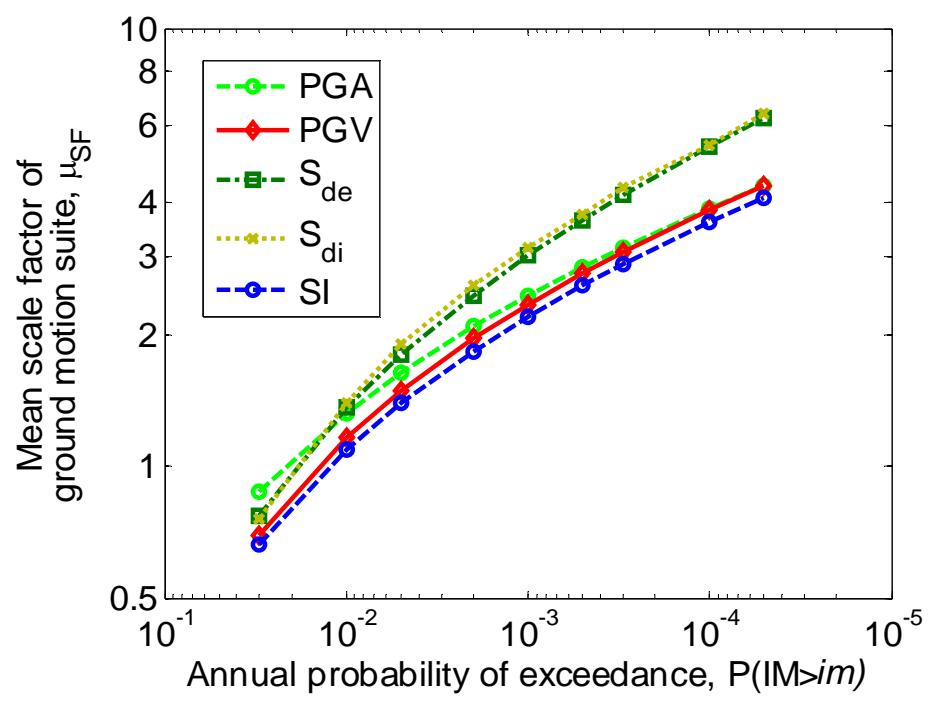

Figure 4: Mean scale factors of ground motion suite using various IMs.

\section{Probability of structural collapse}

Within the PEER PBEE framework, performance with respect to structural collapse can be computed by combining the probability of collapse for a given IM, $P(C \mid I M=i m)$, with the ground motion hazard curve, $P(I M>i m)$ to obtain the probability of structural collapse, $P_{C}$ [9]:

$$
P_{C}=\int_{I M} P(C \mid I M=i m)\left|\frac{P(I M>i m)}{d I M}\right| d I M
$$

$P(C \mid I M=i m)$ is initially estimated from the proportion of ground motion records which cause structural collapse (defined as sidesway collapse and identified by numerical instability [8]) when scaled to $\mathrm{IM}=i m$ and then corrected using Equation (10). As $P(C \mid I M=i m)$ is 
generally assumed to have a lognormal distribution [9], then the values of $P(C \mid I M=i m)$ found at the nine IM levels were used to determine the parameters of this distribution using a generalised linear model (GLM) with a probit link [10]. A GLM is used as it allows for nonconstant variance as opposed to conventional Gaussian regression. Figure 5 illustrates the cumulative probability of structural collapse as a function of the IM exceedance probability. Important parameters of the lognormal distribution of collapse probability are given in Table 2. Firstly, Table 2 illustrates that the dispersion, $\sigma_{\ln I M \mid C}$, for the collapse fragility is highly correlated to the efficiency of the prediction of the maximum interstorey drifts over all floors of the structure [7], with $S_{d e}$ and $S_{d i}$ being the most efficient, followed by $S I, P G V$ and lastly $P G A$. In particular, the large dispersion in the collapse fragility using $P G A$ was not able to be reduced significantly using the 'correction' procedure as the logistic regression was insignificant when a small proportion of collapses occurred. Secondly, the collapse probability obviously depends on the predictability of the IM. For example at $\mathrm{P}_{\mathrm{IM}>i m}=5 \times 10^{-5}$, using $S I$ gives a collapse probability of approximately 0.34 compared to approximately 0.72 using $S_{d e}$. Figure 4 indicates that for $\mathrm{P}_{\mathrm{IM}>i m}=5 \times 10^{-5}$ the mean scale factor using SI is 4.1, while it is 6.2 using $S_{d e}$. Using Figure 4 in an inverse manner gives a scale factor using $S_{d e}$ of approximately 4.1 when $\mathrm{P}_{\mathrm{IM}>i m}=3 \times 10^{-4}$, an exceedance probability at which the collapse probability is approximately $0.31 \mathrm{using} S_{d e}$ (Figure 5). Hence, for a scale factor of approximately $4.1, S I$ and $S_{d e}$ give collapse probabilities of 0.34 and 0.31 , respectively. Thus, with the exception of $P G A$, the significant difference between the collapse distributions is primarily due to the IM predictability.

Table 2: Details of the collapse capacity of the structure using different IMs.

\begin{tabular}{|c|c|c|c|c|}
\hline $\mathrm{IM}$ & Median, $\overline{I M \mid C}$ & $\sigma_{\ln I M \mid C}$ & $P\left(C \mid I M_{2 \mid 50}\right) *$ & $P_{C}\left(\mathrm{x} 10^{-4}\right)$ \\
\hline$P G A(\mathrm{~g})$ & 1.45 & 0.70 & 0.18 & 5.0 \\
\hline$P G V(\mathrm{~cm} / \mathrm{s})$ & 107 & 0.44 & 0.10 & 2.1 \\
\hline$S_{d e}(\mathrm{~cm})$ & 43.3 & 0.38 & 0.21 & 3.8 \\
\hline$S_{d i}(\mathrm{~cm})$ & 38.3 & 0.39 & 0.24 & 5.2 \\
\hline$S I(\mathrm{~cm} . \mathrm{s} / \mathrm{s})$ & 425 & 0.41 & 0.06 & 1.15 \\
\hline
\end{tabular}

$* \mathrm{IM}=I M_{2 \mid 50}$ has a $2 \%$ (Poissonian) probability of exceedance in 50 years.

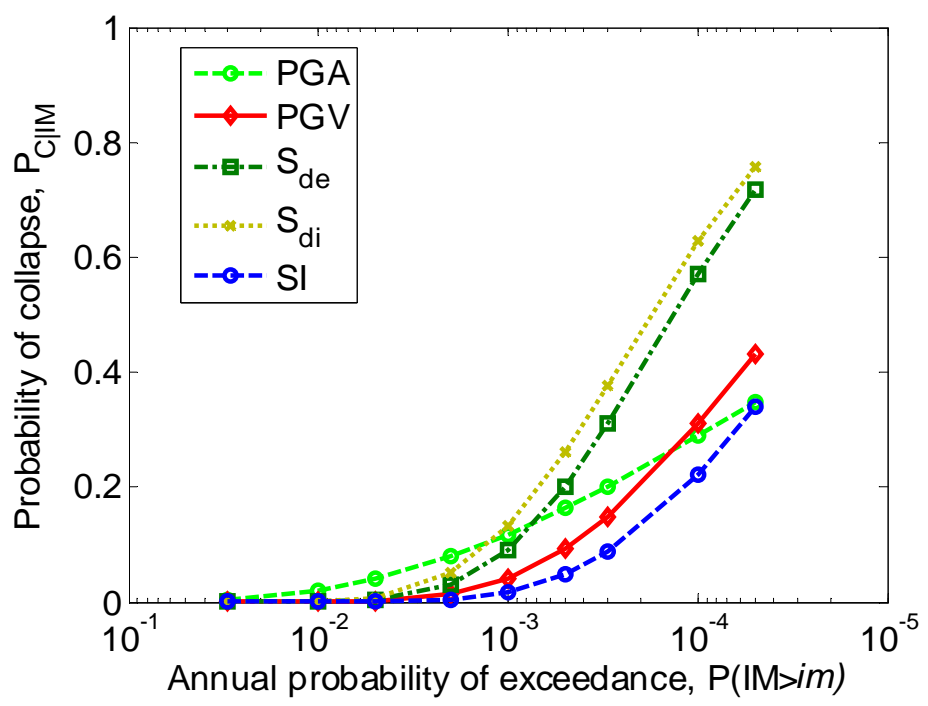

Figure 5: Probability of structural collapse as a function of IM equivalent annual exceedance probability. 


\section{Seismic demand hazard}

The seismic demand hazard can be computed in a similar manner to the collapse hazard, by combining the distribution of structural response for a given ground motion intensity, $P(E D P>e d p \mid I M=i m)$, with the seismic hazard curve:

$$
P_{e d p}=\int_{I M} P(E D P>e d p \mid I M=i m)\left|\frac{P(I M>i m)}{d I M}\right| d I M
$$

where $P_{e d p}$ is the probability of exceeding $\mathrm{EDP}=e d p$.

In Equation (12), for each IM the seismic hazard curve, $P(I M>i m)$, is obtained from Bradley et al. [7, Figure 1], while the seismic response distribution, $P(E D P>e d p \mid I M=i m)$, is obtained from seismic response analysis after using the previously proposed correction procedure. Figure 6 illustrates the demand hazard curves for floor acceleration and interstorey drift ratios at both lower and upper floors in the case study structure. There is a negligible difference in the demand hazard curves using the various IMs at small EDP levels. It should be noted that the asymptotic values of the demand hazard are equal to the annual collapse probability, $P_{c}$, given in Table 2. For EDP values which have an exceedance probability of less than $10^{-2}$, the difference in the demand hazard curves for the different IMs becomes evident. As the demand hazard depends on both the structural response distribution and ground motion hazard, then both IM efficiency (i.e. uncertainty in the EDP|IM distribution) and IM predictability (i.e. affecting the seismic hazard curve, $P(I M>i m)$ ) are important. Both of these two aspects are clearly evident in Figure $6 a$ which illustrates that for the $2^{\text {nd }}$ floor peak acceleration, the demand hazard computed using $P G A$ lies below that of $P G V, S_{d e}$ and $S_{d i}$, for accelerations up to approximately $1.0 \mathrm{~g}$ because of its high efficiency [14, Figure 5]. Similar results for the maximum roof acceleration (Figure 6b) are observed as in the case of the Figure 6a, except that the demand hazard using PGA (relative to the other IMs) is increased because it is less efficient at predicting accelerations in upper floors, which contain significant modification from the characteristics of the structural vibration. Figure $6 \mathrm{c}$ illustrates the $3^{\text {rd }}-4^{\text {th }}$ floor interstorey drift ratio hazard. It is clearly seen that using $P G A$ results in the largest hazard because of its poor efficiency, while $P G V$ and $S I$, both give lower demand hazards than $S_{d e}$ and $S_{d i}$, because of their superior predictability [14, Table 3] despite having slightly lower efficiency [14, Figure 4]. The maximum $10^{\text {th }}$ floor-roof interstorey drift ratio hazard illustrated in Figure 6d shows similar trends as in Figure 6c.

As previously noted, representing a complex ground motion with a simple IM generally results in increased uncertainty in seismic response analysis and, with all other things being equal, gives a greater exceedance probability for a given level of demand than that which would be obtained by bypassing the IM approach (e.g. [6, Chapter 6]). All of the four plots in Figure 6 therefore illustrate that the velocity-based IM's (i.e. SI and $P G V$ ) are the preferred IM's in terms of reducing the demand hazard, due to their high predictability despite not having the lowest efficiency. The theoretical reason for the relative importance of efficiency and predictability in reducing the demand hazard (as well as the loss estimation results to follow) is given in the discussion section later in the manuscript. 

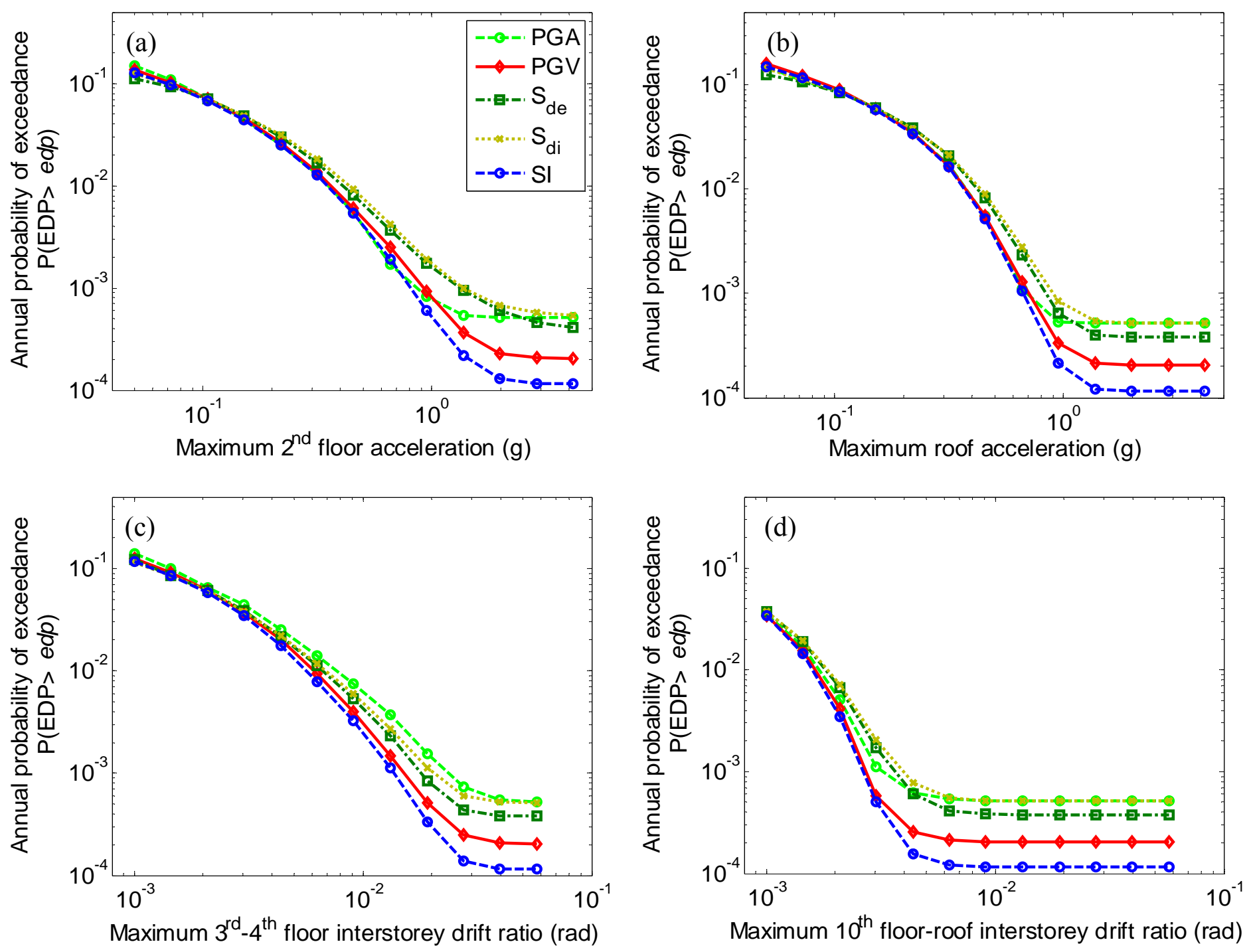

Figure 6: Demand hazard curves for: (a) maximum $2^{\text {nd }}$ floor acceleration; (b) maximum roof acceleration; (c) maximum $3^{\text {rd }}-4^{\text {th }}$ floor interstorey drift ratio; and (d) maximum $10^{\text {th }}$ floor-roof interstorey drift ratio.

\section{SEISMIC LOSS ESTIMATION}

The ultimate goal of a seismic performance assessment is to estimate the consequences/losses to the entire structure, contents and occupants due to the occurrence of an earthquake event. Seismic loss estimation methods can be used to quantitatively assess seismic performance by considering the component inventory of the structure, and their vulnerability. Here the effect of IM selection on seismic loss estimation of the case study structure is illustrated. Only direct repair losses are considered, owing to their maturity compared to the consideration of other losses such as human casualties and business disruption. The effects of economic loss amplification ('demand surge') and cumulative damage due to aftershocks are not considered.

When conducting a loss assessment of a structure, it is important to consider all of the components which have the potential to significantly contribute to the loss due to earthquakes causing a wide range of shaking intensities. Taghavi and Miranda, [15] illustrate that structural, non-structural and contents components are significant contributors to the total cost in office, hotel and hospital buildings. The components considered in the case study structure 
are listed in

Table 3. It was assumed that all of the contents and non-structural components were equally distributed over the height of the building with the exception of the roof mounted equipment (located on the roof only), server and network equipment (located on the $3^{\text {rd }}, 6^{\text {th }}$, and $10^{\text {th }}$ floors), and elevators (ground floor).

\section{Mathematical basis of loss estimation}

All components which are used to describe the structure and its inventory are defined by fragility and loss functions. Fragility and loss functions can be combined (for a single component) to obtain the relationship between component loss for a given $E D P(L \mid E D P)$ (e.g. [1]). From the results of seismic response analysis a relationship can be found between ground motion intensity measures (IM's) and various EDP's throughout the structure. This $E D P \mid I M$ relationship can be combined with the $L \mid E D P$ relationship to obtain a relation between the loss for a single component, $k$, (which is dependent on $E D P_{i}$ ) given a certain level of $\operatorname{IM}\left(L_{k} \mid I M\right)$ :

$$
\begin{gathered}
\mu_{L_{k} \mid I M}=\int \mu_{L_{k} \mid E D P_{i}} f_{E D P_{i} \mid I M} \mathrm{~d} E D P \\
\sigma_{L_{k} \mid I M}^{2}=\int\left[\mu_{L_{k} \mid E D P_{i}}^{2}+\sigma_{L_{k} \mid E D P_{i}}^{2}\right] f_{E D P_{i} \mid I M} \mathrm{~d} E D P-\mu_{L_{k} \mid I M}^{2}
\end{gathered}
$$

where $\mu_{L_{k} \mid I M}$ is the mean loss for component $k$ given $I M=i m ; f_{E D P_{i} \mid I M}$ is the probability density function of $E D P_{i}$ given $I M=i m ; \mu_{L_{k} \mid E D P_{i}}$ is the mean loss for component $k$ given $E D P_{i}=e d p_{i}$; and $\sigma_{L_{k} \mid E D P_{i}}^{2}=$ the variance in the loss for component $k$ given $E D P_{i}=e d p_{i}$.

Equations (13) and (14) can be used to obtain the first two moments for the distribution of loss given $I M$ for a single component $k$. For the case where the structure does not collapse it is reasonably assumed that the total direct repair loss for the entire structure can be obtained from the summation of the direct repair losses in each component. More specifically:

$$
\begin{gathered}
\mu_{L_{T} \mid I M, N C}=\sum_{k=1}^{N c} \mu_{L_{k} \mid I M} \\
\sigma_{L_{T} \mid I M, N C}^{2}=\sum_{k=1}^{N c} \sigma_{L_{k} \mid I M}^{2}+2 \sum_{k=1}^{N c} \sum_{k^{\prime}=1}^{k-1} \sigma_{L_{k}\left|I M, L_{k^{\prime}}\right| I M}
\end{gathered}
$$

where $\mu_{L_{T} \mid I M, N C}$ and $\sigma_{L_{T} \mid I M, N C}^{2}$ are the mean and variance in the total loss given no collapse; $N_{c}$ is the number of components in the structure; and $\sigma_{L_{k}\left|I M, L_{k^{\prime}}\right| I M}$ is the covariance in the $L \mid I M$ relationship between components $k$ and $k$ '.

By considering the mutually exclusive and collective exhaustive events of collapse and no collapse, the expected loss for a given $I M$ can be computed from:

$$
\left.\mu_{L_{T} \mid I M}=\mu_{L_{T} \mid I M, N C} \mid 1-P_{C \mid I M}\right\rfloor+\mu_{L_{T} \mid C} P_{C \mid I M}
$$

where $\mu_{L_{T} \mid C}$ is the mean of the loss given global collapse (assumed independent of $\left.I M\right) ; \mu_{L_{T} \mid I M}$ is the mean of the total loss once conditioning on collapse (and no collapse) has been removed; and $P_{C \mid I M}$ is the probability of collapse given $I M$. The standard deviation of the total loss given $I M, \sigma_{L_{T} \mid I M}^{2}$, although not shown here can be computed in a similar manner (See [3, 
16] for details).

Table 3: Components and quantities used in the case study loss estimation

\begin{tabular}{|c|c|c|c|}
\hline Component & Description & Quantity & Reference \\
\hline $\begin{array}{l}\text { Ductile beam-column } \\
\text { joints }\end{array}$ & $\begin{array}{l}\text { Post 1960s ductile beam column joints } \\
\text { ( } 2 \text { beams) }\end{array}$ & 24 / floor & Williams et al. [17] \\
\hline Columns & $\begin{array}{l}\text { Gravity columns (and seismic columns } \\
\text { on first floor) }\end{array}$ & $\begin{array}{c}20 \text { on } 1^{\text {st }} \text { floor, } 4 \text { on all } \\
\text { other floors }\end{array}$ & Williams et al. [17] \\
\hline $\begin{array}{l}\text { Slab-beam-column con- } \\
\text { nections }\end{array}$ & Connection of slab to seismic frame & 24 / floor & Aslani [1] \\
\hline Partition & Drywall partitions and finish & $721 \mathrm{~m}^{2} /$ floor & $\begin{array}{c}\text { Aslani [1], ATC-58 } \\
\text { [18], Porter et al. [19] }\end{array}$ \\
\hline Exterior glazing & $1.5 \mathrm{~m} \times 1.8 \mathrm{~m}$ standard glass panes & 99 panes / floor & ATC-58 [18] \\
\hline Acoustical ceiling & $\begin{array}{c}0.6 \mathrm{~m} \times 1.2 \mathrm{~m} \text { tiles with Aluminium } \\
\text { frames }\end{array}$ & 693 tiles / floor & $\begin{array}{l}\text { ATC-58 [18], Porter } \\
\text { et al. }[19]\end{array}$ \\
\hline Automatic sprinklers & $3.7 \mathrm{~m}$ sections of sprinkler piping & 23 sections / floor & Porter et al. [19] \\
\hline $\begin{array}{c}\text { Servers and network } \\
\text { equip }\end{array}$ & Typical & $\begin{array}{l}\$ 260,000 \text { on floors } 3,6, \\
\text { and } 10\end{array}$ & ATC-58 [18] \\
\hline Computers and printers & Typical & $\$ 93000$ / floor & ATC-58 [18] \\
\hline $\begin{array}{l}\text { Bookcases and file cabi- } \\
\text { nets }\end{array}$ & Typical & $\$ 16200$ / floor & ATC-58 [18] \\
\hline Roof mounted equipment & Coolers, airconditioning etc. & $\$ 600,000$ on roof & ATC-58 [18] \\
\hline Workstation desks & Typical & $\$ 21600$ / floor & Buchan [20] \\
\hline $\begin{array}{l}\text { Generic acceleration sen- } \\
\text { sitive }\end{array}$ & $\begin{array}{l}\text { fire protection systems, HVAC, Heat- } \\
\text { ing, cooling, pumps, plumbing, toilets }\end{array}$ & $\$ 100,000 /$ floor & Aslani [1] \\
\hline Generic drift sensitive & vertical piping, bath tubs, F.H.C, Ducts & $\$ 100,000 /$ floor & Aslani [1] \\
\hline
\end{tabular}

\section{Mean and standard deviation of loss given intensity}

Figure 7a illustrates the expected loss given intensity (at equivalent probabilities of exceedance obtained from seismic hazard curves [7]) computed for the case study structure using the five IMs. It is noted that when shown in logarithmic scale the comparative trend between the different IM's is very similar to the mean scale factor applied to the ground motion suite as shown in Figure 4. The expected loss for a given IM depends on both the predictability of the IM (giving the equivalent probability of exceedance); the efficiency of the IM at predicting the spatially distributed demands in the structure; and the uncertainty in the damage states of the components in the structure [1,3] (which are obviously independent of the choice of IM). In Figure $7 \mathrm{a}$ it is clear that the difference between the IMs in terms of predictability is more significant than the difference in efficiency, with the hierarchy of the IMs closely related to the predictability (e.g. as shown by the similarity of Figure 4 and Figure 7a). It should be noted that the reason for the reduction in the expected loss with increasing intensity based on PGA, relative to other IMs, is because of the large uncertainty in the collapse fragility curve using PGA. This large uncertainty means that it is more likely to have collapse at small IM levels (increasing the total loss), but less likely (compared to other IMs) at smaller exceedance probabilities (e.g. Figure 5). 

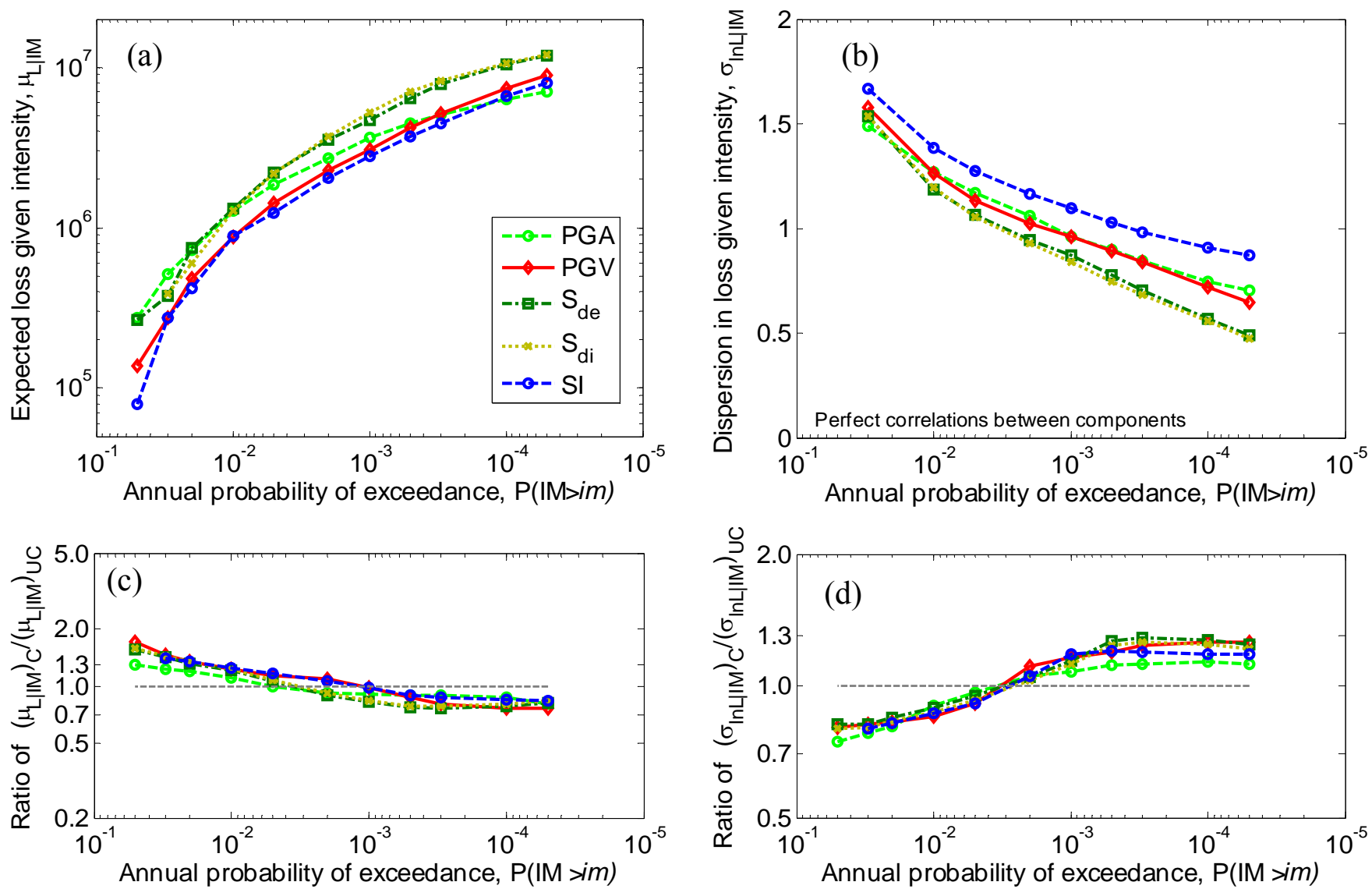

Figure 7: Loss given intensity measure at equivalent exceedance probabilities: (a) expected loss; (b) dispersion in loss (perfect correlations); (c) ratio of corrected and uncorrected expected loss; and (d) ratio of corrected and uncorrected dispersion in loss.

In addition to the expected loss, uncertainty in loss given intensity is also important. The uncertainty depends on the correlations between demand, damage, and loss for different components (via $\sigma_{L_{k}\left|I M, L_{k}\right| I M}$ in Equation (16)). The consideration of component correlations in seismic loss estimation is complicated by a lack of empirical data for their determination and mathematical methodologies for their consideration. Further details on the consideration of correlations in such a framework as that presented here can be found in Bradley and Lee [21]. As it is not the focus in the present study only the upper and lower bound assumptions of perfect and no correlations have been considered herein.

Figure $7 \mathrm{~b}$ illustrates the lognormal standard deviation (dispersion) in the loss given intensity (for an equivalent exceedance probability) when perfect correlations are assumed between demand, damage and loss in different components. As the ground motion intensity increases the dispersion in the loss reduces (while the expected loss increases), as also noted by Krawinkler [22, Figure 6.2]. Hence, for a given probability of exceedance (obtained from a seismic hazard curve) those IMs which give the lowest expected loss will consequently give a higher dispersion in loss (which is observed when comparing the different IM's in Figure 7a and $7 b$ ).

Figure $7 \mathrm{c}$ and Figure $7 \mathrm{~d}$ illustrate the ratios of the corrected to uncorrected losses for the mean and dispersion of the loss. It can be seen that while there is some differences between the different IMs, there is a clear trend in the ratios as a function of the annual exceedance probability. Figure 7c illustrates that the mean corrected losses are larger for large exceedance probabilities and smaller for small exceedance probabilities. The first of these 
observations can be directly attributed to the effect of epsilon (and not to correction of the collapse probability, which was generally statistically insignificant for these exceedance rates), since from Figure 1 it can be seen that the magnitude and distance distributions are very similar for this exceedance probability. The reduction in loss at small exceedance probabilities can also be attributed to correction of epsilon, but also affected by a reduction in the corrected collapse probability, as also observed by Haselton [8]. While Figure 7c illustrates that corrected expected loss is reduced for small exceedance probabilities, Figure $7 \mathrm{~d}$ illustrates that the corrected dispersion in the loss increases. This observation is due to the reduction in the collapse probability at these small exceedance probabilities, which increases the contribution of the uncertainty due to non-collapse (see Bradley and Lee [23] for further details).

While predictability of an IM appears to be the dominant effect from the preceding paragraphs, the efficiency of the various IMs, however, affects on distribution of the loss for a given intensity. This effect is particularly noticeable in terms of the contribution of acceleration- and displacement-sensitive components. Figure 8 illustrates the deaggregation of the expected loss given intensity (which has a $1 / 475$ probability of exceedance) using $P G A$ and $S_{d e}$. Figure 7 illustrates that at this probability of exceedance, the expected loss using the two IMs is similar. As $P G A$ is efficient at predicting acceleration demands, but inefficient at predicting displacement demands (and vice versa for $S_{d e}$ ), then the deaggregation of the expected loss using PGA indicates a reduction in the proportion of losses due to accelerationsensitive components (e.g. acoustical ceiling, computers, servers/network, roof mounted equipment, elevator) compared to $S_{d e}$. Similarly, using $S_{d e}$ results in a reduction of the proportion of losses due to drift-sensitive components (e.g. beams/columns, slab-frame connections, partitions, paint) compared to $P G A$.
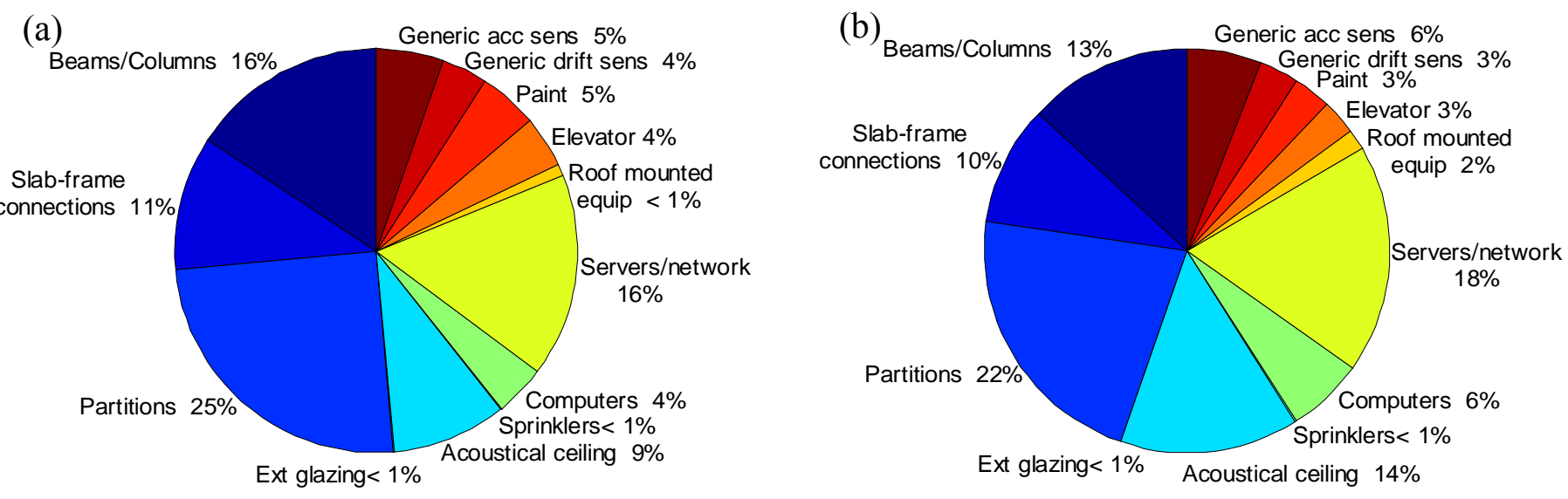

Figure 8: Deaggregation of expected loss at $\mathrm{P}_{\mathrm{IM}>i m}=1 / 475$ using: (a) $\mathrm{IM}=P G A$; and (b) $\mathrm{IM}=S_{d e}$.

Figure 8 illustrates that for the particular structure considered the loss is significantly contributed to by structural, non-structural, and contents components, which are sensitive to both drift and acceleration demands throughout the structure. These features of the loss for this particular structure should be borne in mind when interpreting the results of the loss estimation presented in both this and the next section. Alternatively, if this same 10 storey frame structure represented a hospital building, with earthquake losses likely to be primarily due to damaged medical contents, then it is likely that $P G A$ would be the most appropriate IM because of its efficient prediction of acceleration demands. 


\section{Loss hazard}

The loss hazard is computed by integrating the distribution of loss for a given intensity (defined by the mean and standard deviation discussed above) and the ground motion hazard curve and gives the probability of exceeding a specified level of direct repair loss (i.e. excluding casualties and business disruption):

$$
\lambda_{L_{T}}=\int G_{L_{T} \mid I M}\left|\frac{d \lambda_{I M}}{d I M}\right| d I M
$$

where $G_{L_{T} \mid I M}$ is the CCDF of the total loss given IM.

Figure 9a and 9b illustrate the resulting loss hazard curves for the cases of zero and perfect component correlations, respectively, while Table 4 provides numerical values for the $1 / 475$ and $1 / 2475$ exceedance probabilities. With either assumption it can be seen that using $S I$ and $P G V$ give the smallest probability of exceedance for a given loss or vice versa. This result is due to the high predictability of $S I$ and $P G V$, and the fact that they are also relatively efficient at predicting the spatially distributed acceleration and displacement demands in the case study structure [7]. The relative hierarchy of the other IMs is dependent on the value of loss being considered, with PGA being the highest over small loss values, but then dropping below $S_{d e}$ and $S_{d i}$ at higher loss values. The reason for the relatively poor performance of $S_{d e}$ and $S_{d i}$ is that they are have a poor predictability (relative to the other IMs), and despite providing high efficiency for peak interstorey drift ratios in the central portion of the structure (where the maximum drift ratios occur over the height of the structure), they are inefficient at predicting peak floor accelerations, and interstorey drifts in upper floors which are dominated by higher vibration modes.
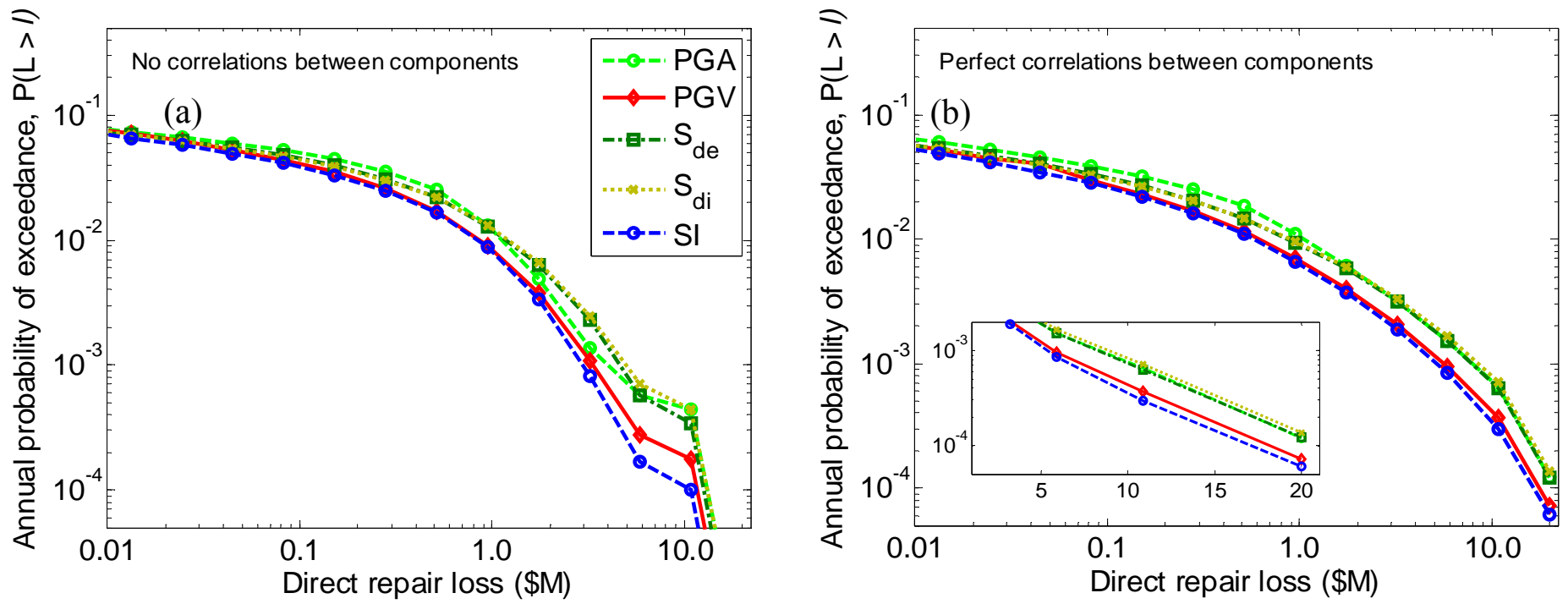

Figure 9: Loss hazard curves for: (a) no correlations between components; and (b) perfect correlations between components.

Table 4: Tabulated loss values for specified exceedance probabilities.

\begin{tabular}{|c|c|c|c|c|c|c|}
\hline \multirow{2}{*}{$\begin{array}{c}\text { Exceedance } \\
\text { probability }\end{array}$} & \multirow{2}{*}{$\begin{array}{c}\text { Correlation } \\
\text { assumption }\end{array}$} & \multicolumn{5}{|c|}{ Loss $(\$ \mathrm{M})$ given exceedance probability } \\
\cline { 3 - 7 } & & $P G A$ & $P G V$ & $S_{d e}$ & $S_{d i}$ & $S I$ \\
\hline $1 / 475$ & None & 2.8 & 2.5 & 3.5 & 3.6 & 2.3 \\
\cline { 2 - 7 }$\left(2.1 \times 10^{-3}\right)$ & Perfect & 5.1 & 3.4 & 5.1 & 5.3 & 3.2 \\
\hline $1 / 2475$ & None & 11.0 & 5.2 & 9.2 & 11.0 & 4.4 \\
$\left(4.0 \times 10^{-4}\right)$ & Perfect & 15.0 & 10.6 & 15.0 & 15.8 & 10.0 \\
\cline { 2 - 7 }
\end{tabular}




\section{DISCUSSION}

Uncertainties in both the prediction of ground motion (predictability) and seismic response (efficiency) affect the computation of the demand hazard. The total uncertainty in the seismic response can be shown to be [24]:

$$
\sigma_{\ln E D P \mid M, R, S}=\sqrt{\sigma_{\ln E D P \mid I M}^{2}+b^{2} \sigma_{\ln I M \mid M, R, S}^{2}}
$$

where $\sigma_{\ln E D P \mid M, R, S}$ is the standard deviation in the demand given magnitude, source-to-site distance, and other site conditions; $\sigma_{\ln E D P \mid I M}^{2}$ is the variance in the demand given intensity (from seismic response analysis); $\sigma_{\ln I M \mid M, R, S}^{2}$ is the variance in the intensity measure given magnitude, source-to-site distance, and other site conditions (from a ground motion prediction equations); and $\mathrm{b}$ is the coefficient in the relationship $\mu_{\ln E D P \mid I M}=a+b \ln I M$. To further simplify Equation (19), Cornell et al. [25] note that $b=1$ is a good approximation for the seismic response of moment frames.

The fact that the total uncertainty in the demand in Equation (19) is of a square-rootsum-of-squares form means that the larger of the two uncertainties will dominate. Consider the prediction of the $3^{\text {rd }}-4^{\text {th }}$ floor interstorey drift ratio of the case study structure. Using $S_{d e}$ the predictability is 0.69 [14, Table 3]; while the efficiency is approximately 0.36 [14, Figure 4]; giving a total uncertainty of $\sqrt{0.69^{2}+0.36^{2}}=0.78$. Alternatively $S I$ has a predictability of 0.59 [14, Table 3] and an efficiency of approximately 0.43 [14, Figure 4] giving a total uncertainty of 0.73 . Because the uncertainty in the ground motion prediction is typically larger than that of the seismic response uncertainty, then it is a more dominant uncertainty in the computation of the demand hazard (as well as loss estimation computations)

The consideration of the importance of both efficiency and predictability can be used to explain the majority of the observations presented in this manuscript (and others for that matter). For example, while inelastic spectral displacement would be expected to give a better prediction than elastic spectral displacements for structures in the non-linear range (i.e. more efficient), Figure 10 of Tothong and Cornell [26] illustrates that as the extent of non-linearity increases (quantified by an R factor) the uncertainty in the prediction of $S_{d i}$ increases up to dispersions of 0.76 . These two differences (i.e. improved efficiency, but reduced predictability) basically negate each other to give the similar demand hazards presented herein. The same argument as above can be made between the use of $P G A$ and $S_{d e}$. Because of its sufficiency and efficiency in predicting peak interstorey drift ratios many have made the comment that $S_{d e}$ is better that $P G A$ (e.g. [24]). It is the demand hazard, however, which should be used for comparing the repercussions of IM selection, as it provides a result which depends on IM efficiency, sufficiency and predictability.

Somewhat of a disclaiming statement is warranted in regard to the previous paragraph. The authors are not suggesting one should simply select those intensity measures which are the most predictable. Recall that bias in the predicted distribution of EDP (sufficiency) was strongly correlated to efficiency of the IM for predicting the EDP. If one is trying to estimate the response of an elastic single-degree-of-freedom system it is unquestionably better to use $S_{d e}$ (which is perfectly efficient and sufficient) than using PGA and having to take care in selecting ground motion records to obtain (practically) the same result. What the authors are simply suggesting is that there is a negative impact on performance assessment if an IM is selected which is difficult to predict and does not strongly relate to the seismic demand being 
predicted. An example from this paper is the use of $S_{d e}$ to predict peak accelerations. In this case $S_{d e}$ is both less efficient and less predictable than $P G A$ resulting in a higher demand hazard. As $P G A$ and $S_{d e}$ give similar hazards for displacement demands then it is the overprediction of the acceleration demands that causes $S_{d e}$ (and $S_{d i}$ for that matter) to result in higher loss estimation results (Figures 7 and 9).

An obvious improvement on the work presented here would be the use of a vectorvalued intensity measure [12], comprising scalar intensity measures which effectively predict high and low frequency dominated seismic responses (accelerations and displacements). Further to this, there is now an emergence of structure-specific demand prediction relationships, where the structure in consideration is subjected to hundreds if not thousands of ground motion records covering a range of magnitude and distance ranges (e.g. [5]). Regression using mixed-effects models can then be performed on the seismic demand (as opposed to simply the seismic intensity as is done to develop ground motion prediction equations). The problems with this approach are obviously the large (but ever-reducing) computational demand; correct selection of the database of records to use (making sure 'host' records are capable of being observed at the 'target' site of the structure); expertise to carry out the regression; and handling of regression equations in the $M_{w}, R$ space poorly constrained by data. Furthermore, if this approach is to be extended to loss estimation, then uncertainties in the component fragility and loss will require regression of uncertain losses for each ground motion in the database, further complicating the regression procedure.

\section{CONCLUSIONS}

This paper has examined the effect of intensity measure (IM) selection on the results of a seismic performance assessment of a 10 storey $\mathrm{RC}$ frame structure. The intensity measures examined were: peak ground acceleration, $P G A$; peak ground velocity, $P G V$; elastic and inelastic spectral displacement, $S_{d e}$ and $S_{d i}$; and spectrum intensity, $S I$.

A method, based on multivariate regression, was proposed to account for the dependence of seismic response on parameters such as moment magnitude, $M_{w}$, source-to-site distance, $R$, and epsilon, $\varepsilon$, such that the same ground motion suite can be used over a range of different ground motion intensity levels.

Comparison of demand and loss hazard curves using the various IMs illustrates that the uncertainty in the ground motion prediction equation (predictability) typically is more significant than uncertainty in the seismic response prediction (efficiency). Most notably, results illustrate that the conventional IM, spectral displacement at the first mode, $S_{d e}\left(T_{l}\right)$, can predict peak drift demands well, but its poor prediction of peak accelerations leads to higher loss estimates than alternative velocity-based IM's, namely spectrum intensity, SI, and peak ground velocity, $P G V$.

The structure used to obtain the loss estimation results presented had a component inventory such that the losses due to drift- and acceleration-sensitive components were both significant in contributing to the total loss. Clearly, if the structure had a different purpose, i.e. a hospital, then the total loss would primarily be comprised by damage to medical equipment which will most likely be acceleration-sensitive. In such a case, $P G A$ is likely to be the most appropiate intensity measure for use in loss estimation.

\section{ACKNOWLEDGEMENTS}

Financial support of the first author from the New Zealand Tertiary Education Commission Bright Futures scheme is appreciated. Constructive comments from two anonymous reviewers are also greatly appreciated. 


\section{REFERENCES:}

[1] Aslani H. Probabilistic earthquake loss estimation and loss disaggregation in buildings. Ph.D. Thesis, John A. Blume Earthquake Engineering Centre, Dept. of Civil and Environmental Engineering Stanford University, 2005, 382.

[2] Goulet CA, Haselton CB, Mitrani-Reiser J, Beck JL, Deierlein GG, Porter K, and Stewart JP. Evaluation of the seismic performance of a code-conforming reinforced-concrete frame building - from seismic hazard to collapse safety and economic losses. Earthquake Engineering and Structural Dynamics 2007; 36(13): 1973-1997, DOI: 10.1002/eqe.694.

[3] Bradley BA, Dhakal RP, Cubrinovski M, MacRae GA, and Lee DS. Seismic loss estimation for efficient decision making. Bulletin of the New Zealand Society for Earthquake Engineering 2009; 42(2): 96-110.

[4] Cornell CA and Krawinkler $\mathrm{H}$. Progress and challenges in seismic performance assessment. PEER Center News 2000; 3(2).

[5] Hancock J, Bommer JJ, and Stafford PJ. Numbers of scaled and matched accelerograms required for inelastic dynamic analyses. Earthquake Engineering and Structural Dynamics 2008; 37(14): 1585-1702, DOI: 10.1002/eqe.827.

[6] Tothong P. Probabilistic Seismic Demand Analysis using Advanced Ground Motion Intensity Measures, Attenuation Relationships and Near Fault effects. PhD thesis, Department of Civil and Environmental Engineering Stanford University, 2007,

[7] Bradley BA, Dhakal RP, Cubrinovski M, and MacRae GA. Prediction of spatially distributed seismic demands in structures: ground motion and structural response. Earthquake Engineering and Structural Dynamics 2009: (submitted).

[8] Haselton CB. Assessing Collapse Safety of Modern Reinforced Concrete Moment Frame Buidlings. Ph.D. Thesis, Department of Civil and Environmental Engineering Stanford University, 2007, 312.

[9] Zareian F and Krawinkler H. Assessment of probability of collapse and design for collapse safety. Earthquake Engineering and Structural Dynamics 2007; 36(13): 1901-1914.

[10] Kutner M, Nachtsheim C, Neter J, and Li W. Applied Linear Statistical Models. Fifth Edition ed. McGraw-Hill/Irwin: New York, 2005; 1396.

[11] Hastie T, Tibshirani R, and Friedman JH. The Elements of Statistical Learning: Data Mining, Inference, and Prediction. Springer: New York, 2001; 533.

[12] Baker JW. Probabilistic structural response assessment using vector-valued intensity measures. Earthquake Engineering and Structural Dynamics 2007; 36(13): 1861-1883.

[13] Baker JW and Cornell CA. Spectral Shape, record selection and epsilon. Earthquake Engineering and Structural Dynamics 2006; 35(9): 1077-1095.

[14] Bradley BA, Dhakal RP, Cubrinovski M, and MacRae GA. Prediction of Spatially Distributed Seismic Demands in Structures: Ground Motion and Structural Response. Earthquake Engineering and Structural Dynamics 2008: (submitted).

[15] Taghavi S and Miranda E. Response assessment of non-structural building elements. Peer Report No 2003/05., 2005. http://peer.berkeley.edu/publications/peer_reports.html

[16] Baker JW and Cornell CA. Uncertainty propagation in probabilistic seismic loss estimation. Structural Safety 2008; 30(3): 236-252.

[17] Williams MS, Villemure I, and Sexsmith RG. Evaluation of seismic damage indices for concrete elements loaded in combined shear and flexure. ACI Structural Journal 1997; 94(3): 315-322.

[18] ATC-58. Guidelines for seismic performance assessment of buildings: ATC-58 35\% Draft. Applied Technology Council, 2007. http://www.atcouncil.org/atc-58.shtml (last accessed 19/11/08)

[19] Porter KA, Kiremidjian AS, and LeGrue JS. Assembly-Based Vulnerability for Buildings and Its Use in Performance Evaluation. Earthquake Spectra 2001; 17(2): 291-312. 
[20] Buchan J. Internal report of non-structural and contents inventories for the Christchurch Council Chambers building. Christchurch, New Zealand., 2007.

[21] Bradley BA and Lee DS. Correlations in structure-specific seismic loss estimation. Earthquake Engineering and Structural Dynamics 2009: (in press).

[22] Krawinkler H. Van Nuys hotel building testbed report: exercising seismic performance assessment. PEER 2005/11 Pacific Earthquake Engineering Research Centre, 2005. 264.

[23] Bradley BA and Lee DS. Accuracy of approximate methods of uncertainty propagation in loss estimation. Structural Safety 2009: (in press), DOI: 10.1016/j.strusafe.2009.04.001.

[24] Shome N, Cornell CA, Bazzurro P, and Carballo JE. Earthquakes, records, and nonlinear responses. Earthquake Spectra 1998; 14(3): 469-500.

[25] Cornell CA, Jalayer F, Hamburger RO, and Foutch DA. Probabilistic basis for 2000 SAC federal emergency management agency steel moment frame guidelines. Journal of Structural Engineering 2002; 128(4): 526-533.

[26] Tothong P and Cornell CA. An Emperical Ground Motion Attenuation Equation for Inelastic Spectral Displacement. Bulletin of the Seismological Society of America 2006; 96(6): 2146-2164. 